\title{
Adaptation to acute coronary syndrome-induced stress with lowering of testosterone: a possible survival factor
}

\author{
Erkki Pesonen, Pirkko Pussinen ${ }^{1}$ and Ilpo Huhtaniemi ${ }^{2,3}$ \\ Department of Paediatrics, Skåne University Hospital, Skåne University, Lund, Sweden, ${ }^{1}$ Oral and Maxillofacial \\ Diseases, University of Helsinki, Helsinki, Finland, ${ }^{2}$ Department of Surgery and Cancer, Institute of Reproductive and \\ Developmental Biology, Hammersmith Campus, Du Cane Road, Imperial College London, London W12 0NN, UK, \\ ${ }^{3}$ Department of Physiology, Institute of Biomedicine, University of Turku, 20520 Turku, Finland
}

Correspondence

should be addressed

to I Huhtaniemi

Email

ilpo.huhtaniemi@

imperial.ac.uk

\begin{abstract}
Objective: The objective of this study was to explore whether circulating testosterone $(T)$ concentration is associated with the occurrence and risk for acute coronary syndromes (ACS).

Method: This case-control study included male patients with acute myocardial infarction (AMI) ( $n=174)$ or unstable angina pectoris (UAP) $(n=90)$ and healthy controls $(n=238)$. Patients gave serum samples during the acute $(n=264)$ and recovery $(n=132)$ phases after a median of 10.5 months after the incident event. Secondary events (ACS or cardiovascular death) were registered during the following 6 years.

Results: During the acute phase, AMI and UAP patients had similar significantly reduced concentrations of serum testosterone in comparison to controls. Testosterone associated inversely with weight, the degree of inflammation

(i.e. C-reactive protein concentration) and signs of a chronic infection. In a multiadjusted Cox regression, when compared to testosterone concentrations considered high-normal (14.91-34.0 nmol/l), low-normal testosterone (9.26-14.90 $\mathrm{nmol} / \mathrm{l})$ in the acute phase predicted better prognosis for cardiovascular death rate with a hazard ratio (HR) of $0.17(0.04-0.68, P=0.012)$. The increased testosterone concentrations after the recovery period did not associate with future cardiovascular disease events. Conclusion: Low-normal testosterone levels in the acute phase of ACS predicted better survival. The observation may indicate better adaptation to stress in survivors and warrants further study.
\end{abstract}

\section{Introduction}

Testosterone (T) replacement therapy has been recommended for men with coronary heart disease (1). However, recent findings suggest an association between testosterone treatment and increased risk for cardiovascular events $(2,3,4,5,6)$. It remains a matter of debate whether low testosterone concentration is an actual risk factor or a consequence of coronary disease.

Reports on the role of circulating testosterone as a risk factor of ischemic heart disease are confusing. In patients with a previous history of cardiovascular disease (CVD) events, hypogonadism has been reported to associate with a reduced risk of new CVD events (6). On the other hand, low serum testosterone concentration has also been proposed to predict increased cardiovascular risk $(7,8)$.

We aimed to clarify the dynamics of serum testosterone concentrations in patients with acute coronary syndromes (ACS). Firstly, the association of testosterone concentration with ACS was analyzed in a cross-sectional case-control population. Secondly, the testosterone concentrations were compared in patients during the

Published by Bioscientifica Ltd. 
acute and recovery phases. Thirdly, the association of testosterone concentrations with subsequent CVD events was analyzed in the follow-up of the patients. The role of infections/inflammation as stressful agents possibly affecting the testosterone response was also addressed.

\section{Methods}

\section{Study population and diagnoses}

The inclusion criteria for the study population $(n=502$ men) were age under 80 years and no signs of cognitive intellectual disability. Cases consisted of 264 male patients, who were admitted for ACS to the CICU in Lund University Hospital between March 1999 and April 2002, as described in detail earlier (9). The 238 controls were selected from the same suburbs, as the patients and the groups were matched with age \pm 2 years. Inclusion criteria of the controls were: i) no history of definite or suspected coronary heart disease or stroke; ii) no operations or chemotherapy within the previous 4 weeks; iii) no medication for diabetes, hypertension or dyslipidemia; and iv) no history of angina, i.e. chest pain, in any location related to exercise and relieved by rest.

The participants completed questionnaires on general background characteristics and demographic data including smoking, marital status, socio-economic data and the medical history of the family.

Of the patients, 21 died before they could be interviewed. Of the invited patients, 48 chose not to participate. After admission, 12 patients were excluded from the study with the following diagnoses: unspecified precordial pain (seven patients), atrial fibrillation, pericarditis, myocarditis, pulmonary embolism and aortic aneurysm. Of the participants, whose testosterone analyses were available, acute myocardial infarction (AMI) was diagnosed according to the prevailing criteria in 2002 in 174 individuals and unstable angina pectoris (UAP) in 90. AMI was diagnosed if two of the following criteria were fulfilled: i) typical chest pain lasting over $20 \mathrm{~min}$; ii) ST elevations followed by testosterone wave inversion or new $\mathrm{Q}$ waves in the ECG; or iii) an increase in creatine kinase isoenzyme MB (CK-MB) to more than twice the upper limit of the normal range. UAP was diagnosed in patients with: i) continuous ischemic chest pain; ii) transient or persistent ST segment depression in the ECG $(<1 \mathrm{~mm})$; and/or iii) elevation of CK-MB $(5<\mathrm{CK}-\mathrm{MB}<10 \mu \mathrm{g} / \mathrm{l})$ or troponin testosterone ( $\mathrm{TnT}$ ) $(0.05<\mathrm{TnT}<0.10 \mu \mathrm{g} / \mathrm{l})$. Coronary angiograms were done in 164 patients.

\section{Recovery samples and follow-up}

The recovery phase samples were taken from 132 males (50\%) (84 with AMI and 48 with UAP) after the minimum recovery of 6 months (median 314, interquartile reage (IQR) 178-689 days). We followed 264 patients for up to a median 5.6 years (IQR 4.6-6.5) and recurrent ACS and cardiovascular deaths via the hospital records and population register. Follow-up samples were collected from all patients that were available and gave their consent.

\section{Laboratory determinations}

A research nurse made a visit to the control persons within 5 days. Blood samples were taken the first thing in the morning during the working hours of the nurses, usually around $0900 \mathrm{~h}$ and never after $1400 \mathrm{~h}$. The mean (s.D.) testosterone concentration in the patient samples taken at 0700-1400, 1400-2200 and 2200-0700 h did not differ significantly, i.e. 13.3 (9.2), 17.3 (9.3) and 12.3 (6.1) nmol/1 $(P=0.090)$. During follow-up visits, the samples were taken beween 0900 and $1200 \mathrm{~h}$. Blood samples for TnT and CK-MB samples were obtained on admission to the hospital and at 1000 and $2000 \mathrm{~h}$. High-sensitivity serum C-reactive protein (CRP) was measured in patients and controls using nephelometry with polyclonal antibodies and calibrators (Behringwerke AG, Marburg, Germany).

The serum samples were stored at $-20{ }^{\circ} \mathrm{C}$ until laboratory determinations. Testosterone was measured using Spectria RIA kits (Orion Diagnostica, Turku, Finland). The intra- and inter-assay coefficients of

Table 1 Characteristics of cases and controls. Data are presented as mean \pm s.D., geometric mean (1st and 3rd quartile) or as $n(\%)$.

\begin{tabular}{|c|c|c|c|}
\hline & Cases & Controls & $\boldsymbol{P}^{\mathbf{a}}$ \\
\hline$n$ & 264 & 238 & \\
\hline Age (years) & $62.3 \pm 9.4$ & $62.5 \pm 9.2$ & 0.813 \\
\hline Weight (kg) & $85.7 \pm 13.1$ & $80.7 \pm 11.1$ & $<0.001$ \\
\hline Cholesterol $(\mathrm{mmol} / \mathrm{l})$ & $5.27 \pm 1.29$ & $5.66 \pm 0.97$ & $<0.001$ \\
\hline $\operatorname{CRP}\left(\mathrm{mg} / \mathrm{l}^{\mathrm{b}}\right.$ & $9.66(3.08-31.8)$ & $1.57(0.85-2.66)$ & $<0.001$ \\
\hline Testosterone $(\mathrm{nmol} / \mathrm{l})$ & $10.9 \pm 5.6$ & $14.3 \pm 6.3$ & $<0.001$ \\
\hline \multicolumn{4}{|c|}{ Porphyromonas gingivalis } \\
\hline $\lg A(E U)^{b}$ & $2.43(1.51-3.40)$ & $2.24(1.49-3.18)$ & 0.331 \\
\hline $\lg (E U)^{b}$ & $6.46(4.52-8.79)$ & $6.31(4.64-8.84)$ & 0.807 \\
\hline Current smokers & $45(17.0 \%)$ & $43(18.1 \%)$ & $0.765^{c}$ \\
\hline Diabetes & $35(13.2 \%)$ & 0 & - \\
\hline
\end{tabular}

${ }^{a} t$-test, variables with skewed distribution (CRP, $P$. gingivalis antibody levels) were log-transformed before analysis.

${ }^{\mathrm{b}}$ Geometric mean (1st and 3rd quartile).

$\chi^{2}$-test. 
variation were 4.6 and $6.5 \%$ respectively. The testosterone concentrations were divided into low (0.5-9.23 nmol/1), intermediate (9.26-14.90 nmol/1) and high (14.91$34.0 \mathrm{nmol} / \mathrm{l}$ ) tertiles representing low, low-normal and high-normal levels.

The following viral and bacterial antibody titers, as reported in our earlier articles $(9,10)$, were used in statistical analyses: Chlamydia pneumoniae, Helicobacter pylori, cytomegalovirus, Herpes simplex virus, enterovirus (9), Aggregatibacter actinomycetemcomitans and Porphyromonas gingivalis (10).

\section{Ethics approval}

The ethical committee of the Lund University has approved this study. The study complies with the Declaration of Helsinki. A written informed consent was obtained from the subjects.

\section{Statistics analysis}

There was $>80 \%$ statistical power $(\alpha 0.05)$ to detect a $1.5 \mathrm{nmol} / 1$ (s.D. $6.0 \mathrm{nmol} / \mathrm{l}$ ) difference in the testosterone concentrations between the groups. Significance of the differences between the groups was analyzed with Student's $t$-test, ANOVA, paired sample $t$-test or $\chi^{2}$ test. Association of the testosterone concentrations with CRP and antibody levels to multiple infectious agents was analyzed with linear regression models adjusted for age and case/control status. The appropriateness of these models was examined by defining residuals and examining residual plots. In the case-control setting, the association of ACS with testosterone tertiles was analyzed by logistic regression models adjusted for: i) age; ii) age, cholesterol and current smoking; and iii) age, cholesterol, current smoking, CRP and weight. Significance of the trend was examined with $\chi^{2}$ test. In the follow-up study,

Table 2 Characteristics of cases and controls in testosterone tertiles. Data are presented as mean \pm s.D., geometric mean (1st and 3rd quartile) or as $n(\%)$.

\begin{tabular}{|c|c|c|c|c|}
\hline & Serum $\mathbf{t}$ & stosterone concentratior & $\mathrm{mol} / \mathrm{l})$ & \\
\hline & Normal-High (14.91-34.0) & Low-normal (9.26-14.90) & Low (0.5-9.23) & $P$ values \\
\hline Cases $(n)$ & 68 & 81 & 115 & \\
\hline Age (years) & $62.6 \pm 8.94$ & $62.2 \pm 9.95$ & $63.0 \pm 8.88$ & $0.802^{\mathrm{a}}$ \\
\hline Cholesterol $(\mathrm{mmol} / \mathrm{l})$ & $5.29 \pm 1.20$ & $5.28 \pm 1.73$ & $5.27 \pm 0.96$ & $0.997^{\mathrm{a}}$ \\
\hline CRP (mg/l) & $8.84(2.41-29.8)^{b}$ & $9.28(3.87-27.4)^{\mathrm{b}}$ & $10.5(2.50-36.8)^{\mathrm{b}}$ & $0.748^{a}$ \\
\hline Weight (kg) & $80.8 \pm 14.0$ & $88.2 \pm 13.1$ & $86.3 \pm 12.3$ & $0.015^{\mathrm{a}}$ \\
\hline BMI $\left(\mathrm{kg} / \mathrm{m}^{2}\right)$ & $19.3 \pm 11.9$ & $21.3 \pm 12.1$ & $24.9 \pm 9.4$ & $0.003^{a}$ \\
\hline Blood pressure (mmH & & & & \\
\hline Systolic & $140 \pm 19$ & $145 \pm 21$ & $139 \pm 15$ & $0.717^{\mathrm{a}}$ \\
\hline Diastolic & $80 \pm 12$ & $79 \pm 16$ & $78 \pm 7$ & $0.881^{a}$ \\
\hline Porphyromonas ging & & & & \\
\hline $\lg A(E U)$ & $2.32(1.47-2.92)^{\mathrm{b}}$ & $2.43(1.67-3.61)^{b}$ & $2.50(1.43-3.81)^{b}$ & $0.688^{a}$ \\
\hline $\lg G(E U)$ & $5.92(4.51-7.47)^{b}$ & $6.43(4.48-9.46)^{\mathrm{b}}$ & $6.80(4.57-9.09)^{b}$ & $0.219^{a}$ \\
\hline Current smokers & $14(20.6 \%)$ & $11(13.6 \%)$ & $20(17.4 \%)$ & $0.522^{c}$ \\
\hline Diabetes & $10(14.7 \%)$ & $10(12.3 \%)$ & $16(13.9 \%)$ & $0.921^{c}$ \\
\hline Beta blockers & $26(38.2 \%)$ & $31(38.3 \%)$ & $41(35.7 \%)$ & $0.842^{c}$ \\
\hline Calcium blockers & $8(11.8 \%)$ & $17(21.0 \%)$ & $14(12.2 \%)$ & $0.154^{c}$ \\
\hline At follow-up & & & & \\
\hline Recurrent ACS & $16(23.5 \%)$ & $23(28.4 \%)$ & $28(24.3 \%)$ & $0.750^{c}$ \\
\hline PTCA & $29(42.6 \%)$ & $39(48.1 \%)$ & $43(37.4 \%)$ & $0.577^{c}$ \\
\hline CABG & $8(11.8 \%)$ & $12(14.8 \%)$ & $21(18.3 \%)$ & $0.219^{c}$ \\
\hline CVD death & $18(26.5 \%)$ & $13(16.1 \%)$ & $14(12.1 \%)$ & $0.692^{c}$ \\
\hline Controls (n) & 98 & 87 & 53 & \\
\hline Age (years) & $62.2 \pm 0.07$ & $61.5 \pm 9.37$ & $64.2 \pm 9.93$ & $0.249^{a}$ \\
\hline Cholesterol ( $\mathrm{mmol} / \mathrm{l})$ & $5.82 \pm 0.97$ & $5.61 \pm 1.03$ & $5.45 \pm 0.85$ & $0.078^{a}$ \\
\hline $\mathrm{CRP}(\mathrm{mg} / \mathrm{l})$ & $1.55(0.81-2.59)^{\mathrm{b}}$ & $1.43(0.76-2.60)^{\mathrm{b}}$ & $1.88(1.09-3.70)^{\mathrm{b}}$ & $0.218^{\mathrm{a}}$ \\
\hline Weight (kg) & $78.7 \pm 9.80$ & $80.7 \pm 11.1$ & $84.5 \pm 12.8$ & $0.021^{a}$ \\
\hline Porphyromonas ging & & & & \\
\hline $\lg A(E U)$ & $2.04(1.43-4.21)^{b}$ & $2.10(1.33-2.93)^{b}$ & $2.92(1.59-5.30)^{b}$ & $0.002^{a}$ \\
\hline $\lg G(E U)$ & $5.99(4.75-8.27)^{b}$ & $6.05(4.23-8.14)^{b}$ & $7.41(5.28-11.4)^{b}$ & $0.02^{a}$ \\
\hline Current smokers & $25(25.5 \%)$ & $14(16.1 \%)$ & $4(7.5 \%)$ & $0.017^{c}$ \\
\hline
\end{tabular}


Table 3 Association of CRP and Porphyromonas gingivalis antibody levels with the testosterone levels. Data are presented as standardized coefficient ( $P$ value).

\begin{tabular}{|c|c|c|c|}
\hline & Cases & Controls & All ${ }^{\mathrm{C}}$ \\
\hline$n$ & 264 & 238 & 502 \\
\hline \multicolumn{4}{|l|}{ P. gingivalis ${ }^{a}$} \\
\hline $\lg A$ & $-0.094(0.166)$ & $-0.134(0.048)$ & $-0.105(0.021)$ \\
\hline $\lg G$ & $-0.129(0.046)$ & $-0.095(0.164)$ & $-0.114(0.011)$ \\
\hline CRP & $-0.127(0.044)$ & $-0.064(0.342)$ & $-0.109(0.046)$ \\
\hline
\end{tabular}

Linear regression model for testosterone levels with logarithmically transformed independent variables adjusted for a age and CRP concentration or 'bage. 'In the column 'All', the models are also adjusted for case/control status.

the association of recurrent ACS and CVD death with testosterone was analyzed in similar models by Cox regression. The variables' interactions with time were tested, and the proportional hazards assumption was not violated.The analyses were performed with PASW Statistics 18.

\section{Results}

\section{Baseline}

Characteristics of the cases and controls are presented in Table 1. ACS patients, when admitted to the coronary care unit, had lower mean (s.D.) serum testosterone concentrations than the controls; these differences were significant for both UAP and AMI patients $(P<0.001)$, but did not differ significantly from each other, 11.3 (5.7) vs 10.8
(5.5) nmol/l $(P=0.494)$. Testosterone tertiles correlated inversely with weight and BMI in cases and also with weight of controls (Table 2), but did not correlate with the sampling time, the time between appearance of cardiac symptoms and blood sampling or the degree of stenosing lesions in the coronary angiograms (results not shown). In multivariate linear regression models, testosterone associated inversely with CRP concentrations and IgA and IgG class antibody levels against $P$. gingivalis (Table 3). Other antibody levels did not associate with testosterone concentrations (not shown).

In a multivariate logistic regression model, ACS associated inversely with testosterone tertiles with an OR (95\% CI) $1.22(0.58-2.59)$ and 2.75 (1.31-5.80) in the lownormal and low tertiles with a significant $P$ value for trend (0.015) (Table 4). Similar trends were seen for both UAP and AMI, but the significance was attenuated after adjusting for weight and CRP.

\section{Follow-up}

The mean testosterone concentrations in patients increased during the recovery period from 11.2 (5.77) to $16.6(6.46) \mathrm{nmol} / \mathrm{l}(P<0.001)$, which did not differ from the values in controls (Fig. 1). This increase was evident in most of the patients $(69.7 \%$ increase, $12.9 \%$ decrease, $17.4 \%$ no change within $\pm 2 \mathrm{nmol} / \mathrm{l})$. The changes were similar in patients with AMI and UAP, 16.7 (6.77) vs 16.2 (5.90) $\mathrm{nmol} / \mathrm{l}$ respectively. The difference between the acute and recovery phases testosterone levels correlated significantly with the time between the two samplings

Table 4 Association of testosterone concentrations with ACS in the case-control population. Data are presented as OR (95\% CI).

\begin{tabular}{|c|c|c|c|c|}
\hline & \multicolumn{3}{|c|}{ Serum testosterone concentrations $(\mathrm{nmol} / \mathrm{l})$} & \multirow[b]{2}{*}{$P$ value } \\
\hline & Normal-High (14.91-34.0) & Low-normal (9.26-14.90) & Low $(0.5-9.23)$ & \\
\hline \multicolumn{5}{|l|}{ ACS } \\
\hline Case/control & $68 / 98$ & $81 / 87$ & $115 / 53$ & \\
\hline Model 1 & 1.00 & $1.34(0.87-2.07)$ & $3.13(2.00-4.91)$ & $<0.001$ \\
\hline Model 2 & 1.00 & $1.34(0.80-2.25)$ & $3.18(1.90-5.32)$ & $<0.001$ \\
\hline Model 3 & 1.00 & $1.22(0.58-2.59)$ & $2.75(1.31-5.80)$ & 0.015 \\
\hline \multicolumn{5}{|l|}{ UAP } \\
\hline Case/control & $23 / 98$ & $24 / 87$ & $43 / 53$ & \\
\hline Model 1 & 1.00 & $1.17(0.62-2.23)$ & $3.46(1.89-6.36)$ & $<0.001$ \\
\hline Model 2 & 1.00 & $1.14(0.47-2.74)$ & $4.15(1.89-9.13)$ & $<0.001$ \\
\hline Model 3 & 1.00 & $1.43(0.45-4.48)$ & $3.51(1.18-10.4)$ & 0.050 \\
\hline \multicolumn{5}{|l|}{ AMI } \\
\hline Case/control & $45 / 98$ & $57 / 87$ & $72 / 53$ & \\
\hline Model 1 & 1.00 & $1.43(0.88-2.32)$ & $2.97(1.80-4.90)$ & $<0.001$ \\
\hline Model 2 & 1.00 & $1.41(0.80-2.51)$ & $2.76(1.54-4.93)$ & 0.001 \\
\hline Model 3 & 1.00 & $1.18(0.49-2.86)$ & $2.36(0.97-5.75)$ & 0.121 \\
\hline
\end{tabular}

$P$ value presented for the trend; Model 1: adjusted for age; Model 2: additionally, adjusted for cholesterol and current smoking; Model 3: additionally, adjusted for CRP and weight. 

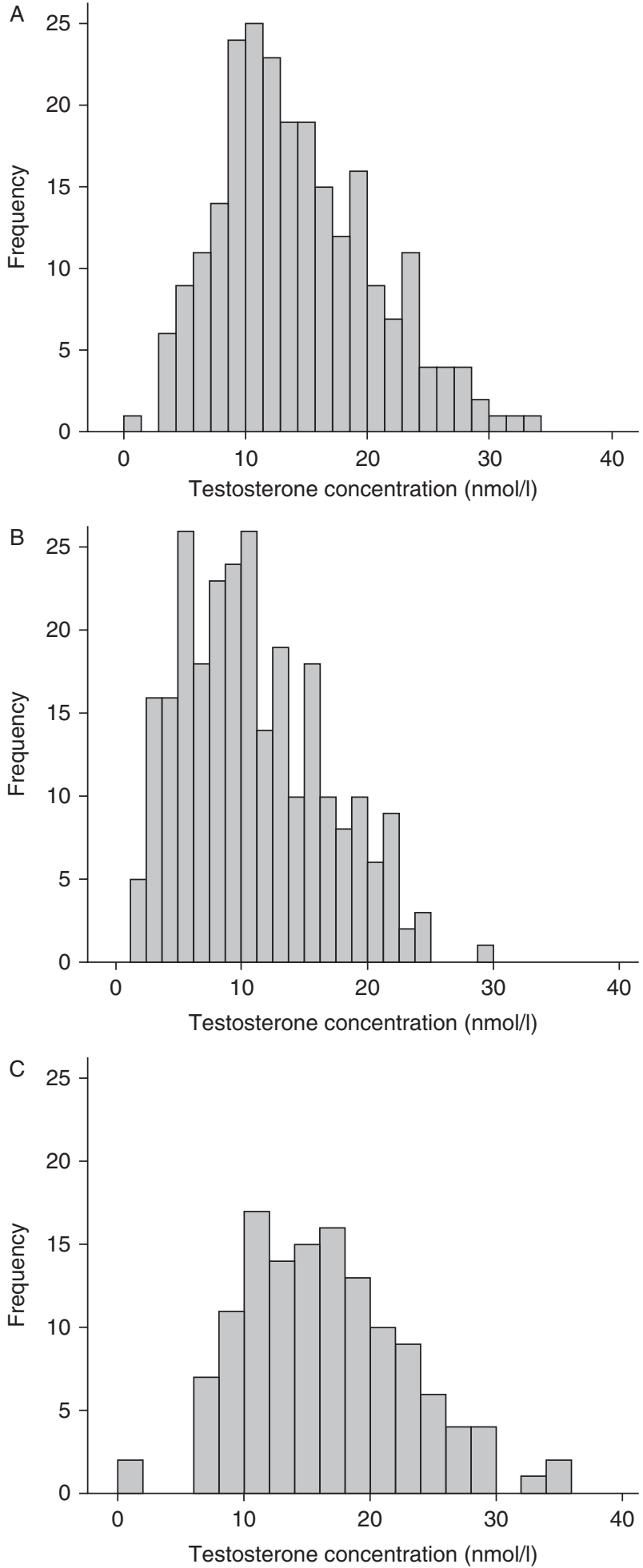

Figure 1

Histograms of the serum testosterone concentrations. The serum testosterone concentrations are shown for $(A)$ healthy controls $(n=238)$ and ACS (AMI and UAP) patients during (B) the acute phase $(n=264)$ and $(C)$ the recovery period $(n=132)$.
( $r=0.256, P=0.005$ for $\Delta$ testosterone (recovery and acute phases)), and the two levels correlated significantly with each other ( $r=0.446, P<0.001$; Fig. 2$)$.

In the follow-up study of the patients, neither the acute nor the recovery phase mean testosterone concentrations differed between those with or without a new event. However, in a Cox regression model compared to the high-normal testosterone levels, the low testosterone level in the acute phase associated with an increased risk of recurrent ACS with a HR $2.77(1.18-6.52, P=0.008)$ when adjusted for age, cholesterol concentration and smoking, but the significance was abolished after adjusting for weight and CRP (Table 5). The lower tertiles of testosterone concentrations in the acute phase associated inversely with the risk of cardiovascular death $(P=0.025$ for trend). After all adjustments, the low-normal testosterone concentration remained inversely associated with the risk of death with a HR $0.17(0.04-0.68, P=0.012)$ (Table 5). The predicted cumulative survival curves according to the Cox regression model for the testosterone levels with covariates age, smoking, cholesterol, CRP and weight are presented in Fig. 3. The result remained unchanged when the Cox regression model was adjusted for the medications when entering the hospital, TnT concentrations, percutaneous transluminal coronary angioplasty (PTCA) or coronary artery bypass grafting (CABG) performed during treatment or the antibody levels to $P$. gingivalis. $\Delta$ testosterone or the recovery phase did not associate with recurrent ACS or cardiovascular death.

\section{Discussion}

\section{Low testosterone levels in the acute phase predict better survival}

ACS was associateted with low-normal testosterone levels in the acute phase. After the acute phase, testosterone concentrations usually increased, but the recovery levels were not associated with future CVD events. The increase in the testosterone levels observed in the recovery phase supports a consequential, rather than causative, role of the low testosterone concentrations. Testosterone concentrations correlated inversely with CRP levels. The temporararily suppressed serum testosterone concentrations during ACS predicted improved prognosis: low-normal testosterone concentration during the acute phase decreased the incidence of CVD deaths in the follow-up of 6 year. 


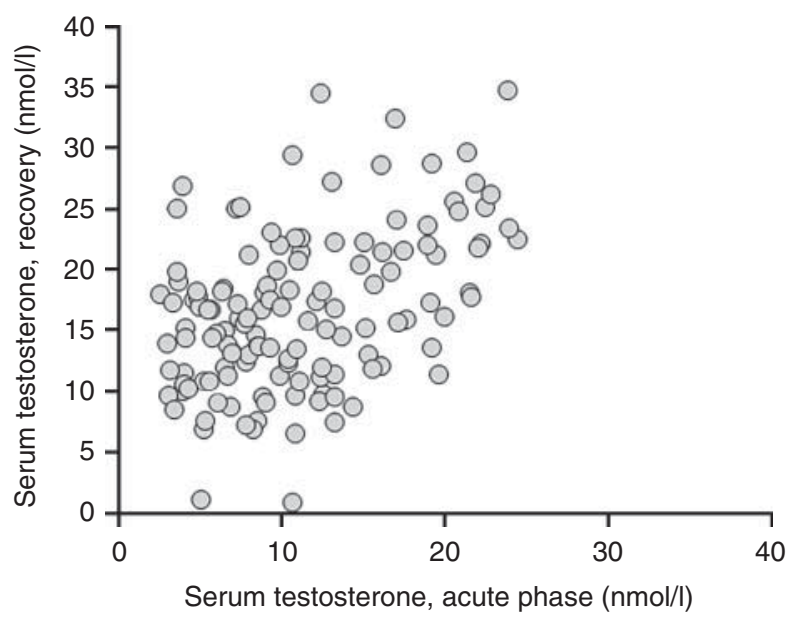

Figure 2

Serum testosterone concentrations during the acute and the recovery phases. The acute phase levels are shown on the $X$-axis and the recovery phase levels on the $Y$-axis $(n=132)$. The mean levels of testosterone were significantly higher after 11 months' recovery period $(P<0.001)$.

\section{The controversy of testosterone and CVD}

Cross-sectional observational studies suggest that low testosterone concentration is a risk factor for CVD. There is an inverse relationship between endogenous serum testosterone levels and coronary heart disease in males $(8,11,12)$ although all studies cannot confirm this finding $(6,13,14,15,16)$, and the direction of causality of the phenomenon remains unclear. Moreover, a decreased serum testosterone concentration has been shown to be associated with acute ischemic strokes, infarct size and mortality (17). These data suggest that normal testosterone levels may offer protection against the development of atherosclerosis in middle-aged men.

Optimal androgen levels seem to be a biomarker for survival because men with mid-range levels of testosterone and dihydro-testosterone were recently reported to have the lowest death rate from any cause (18). This was obvious also in the present study, where intermediate testosterone concentrations (9.26-14.90 nmol/l) considered as 'lownormal' were protective against CVD death in the followup of the patients, and the men with suppressed testosterone in the acute phase had increased risk of subsequent ACS in the follow-up of 6 years. Even if there is some supportive exprimental data (19), the causality between testosterone levels and CVD remains elusive. During the past 4 years, several independent studies, published in prestigious journals, have shown men treated with testosterone to have increased amount of cardiovascular symptoms $(2,3,4$, 5 , 6), which has created heated debate around the testosterone vs CVD issue $(20,21)$.

\section{Stress and clinical implications}

The low testosterone concentrations in ACS patients might be caused by an acute stress even if chronic inflammation may play a contributory role. It is also possible that an acute decrease of testosterone was superimposed on a pre-existing lower testosterone. Suggestions in this direction are the negative association of serum testosterone with weight/BMI (a robust negative determinant of total testosterone in all situations also in healthy men) and the observed correlation between acute and recovery testosterone. However, also an acute suppression due to ACS is involved because of the subsequent increase of testosterone during recovery.

Table 5 Association of testosterone concentrations in the acute phase with recurrent ACS and CVD death in the follow-up of 6 years. Data are presented as HR $(95 \% \mathrm{Cl})$.

\begin{tabular}{|c|c|c|c|c|}
\hline & \multicolumn{3}{|c|}{ Serum testosterone concentrations $(\mathrm{nmol} / \mathrm{l})$} & \multirow[b]{2}{*}{$P$ values } \\
\hline & Normal-High (14.91-34.0) & Low-normal (9.26-14.90) & Low $(0.5-9.23)$ & \\
\hline \multicolumn{5}{|c|}{ Recurrent ACS (67/193) ${ }^{a}$} \\
\hline Model 1 & 1.00 & $1.64(0.86-3.13)$ & $2.81(1.41-5.60)$ & 0.011 \\
\hline Model 2 & 1.00 & $1.85(0.83-4.15)$ & $2.77(1.18-6.52)$ & 0.046 \\
\hline Model 3 & 1.00 & $1.33(0.52-3.41)$ & $2.39(0.89-6.41)$ & 0.171 \\
\hline \multicolumn{5}{|c|}{ CVD death $(45 / 216)^{a}$} \\
\hline Model 1 & 1.00 & $0.69(0.34-1.39)$ & $0.77(0.36-1.64)$ & 0.580 \\
\hline Model 2 & 1.00 & $0.27(0.08-0.93)$ & $0.43(0.12-1.52)$ & 0.098 \\
\hline Model 3 & 1.00 & $0.17(0.04-0.68)$ & $0.26(0.06-1.02)$ & 0.025 \\
\hline
\end{tabular}

$P$ value presented for the trend. Model 1: adjusted for age; Model 2: additionally, adjusted for current smoking and cholesterol; Model 3: additionally, adjusted for CRP and weight.

${ }^{\mathrm{a}}$ Yes/no. 


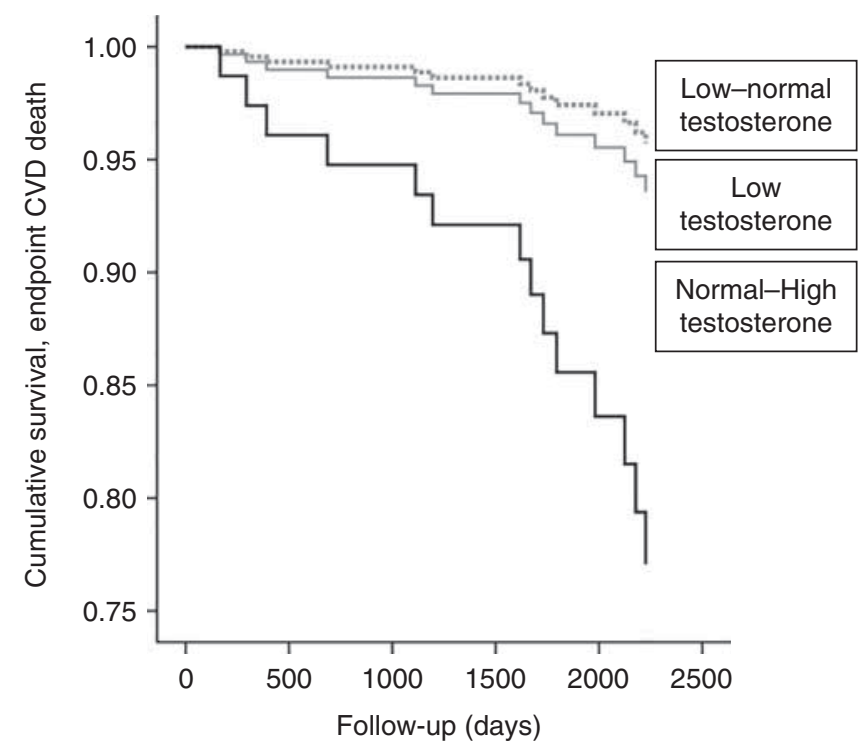

\section{Figure 3}

Predicted cumulative survival of the ACS patients from CVD death in the follow-up of 6 years. The Cox regression model for tertiles of serum testosterone concentration was performed for 261 men and adjusted for age, smoking, cholesterol, CRP and weight. The samples were taken during the acute phase.

Our study suggests that chronic stress in the form of infections may play a role in the 'low testosterone syndrome', since the antibody levels to the major periodontal pathogen, $P$. gingivalis, associated inversely with the testosterone levels both in patients and controls. Periodontitis is one of the most prevalent infectious diseases affecting as many as $75 \%$ of adult and elderly populations, and it eventually leads to loss of teeth. In earlier studies, the results on the association of sex steroids and periodontitis or tooth loss have been contradictory $(22,23)$, but the subject is rarely investigated.

\section{Testosterone levels and survival}

Paradoxically, although the decreased testosterone levels associated with an increased risk of recurrent ACS, they predicted better survival. This may involve better adaptation mechanisms of those with low testosterone concentrations to acute stress, to spare the energy of the body and to deviate it from redundant functions, such as reproduction and energy consumption (6). Therefore, the recent results by Corona et al. (6) suggesting that low testosterone concentration has a protective effect were confirmed in our study. The 'low testosterone syndrome' in these men would be analogous to the 'low T3 syndrome', a state of a suppressed thyroid function in connection with an acute disease, which is not recommended to be treated with thyroid hormone supplementation (24). Alternatevely, it could be analogous to the situation where mild hypothyroidism is associated with better survival in old age $(25,26)$. Besides the thyroid, also testicular hypofunction could be such a survival factor.

\section{Potential study limitations}

The limitations inherent in cross-sectional studies that a single sample of testosterone at a specific time point might not reflect the natural course of a disease are clearly shown in our study. Diurnal variation may decrease the reliability of the interpretations, although in the present study the time of the day did not correlate with the testosterone levels. In the morning, the testosterone levels may be on average $30-35 \%$ higher than the levels measured in the mid- to late afternoon. The observed difference between morning and afternoon declines with age dropping to $\sim 10 \%$ at 70 years of age (27). In our patients, testosterone concentrations were measured immediately after the acute events. The follow-up values which have taken some months after the acute event might not reflect concentrations before the events, although they are probably closer to the individual's normal testosterone concentrations. The medication of the patients may conceal the effects on testosterone.

A good quality immunoassay was used for testosterone measurements; therefore, the hormone data can be considered reliable, although mass spectrometry was not used $(28,29)$. Only total testosterone was measured, because sex hormone-binding globulin (SHBG) levels were not available. Because the men in the highest testosterone tertile had the same age but were $5-10 \%$ lighter than the men with the lower testosterone levels, their SHBG levels were apparently higher (30). Our findings do not support the association of SHBG with a more favorable CVD risk in this older male population, as we have reported recently in healthy young men (16). Another limitation of the current study is the lack of gonadotropin and estradiol measurement.

\section{Conclusion}

Immediately after an acute coronary event, the testosterone concentrations are low, but usually increase thereafter. Stress is probably the cause of decreased serum testosterone concentrations during ACS even though 
chronic inflammation might play a contributory role. These findings should be considered hypothesis generating. They suggest that individuals reacting to stress by lowering of testosterone have better prognosis, since the acutely low-normal testosterone levels have predicted better survival.

\section{Declaration of interest}

The authors declare that there is no conflict of interest that could be perceived as prejudicing the impartiality of the research reported.

\section{Funding}

This work was supported by grants from Lund University, Lund University Hospital and the Yrjö Jahnsson foundation (to PJP) and the Academy of Finland (grant 126650 to PJP).

\section{Author contribution statement}

All authors have participated in the planning of the study, analyzing the data and writing the article. E Pesonen is responsible for collecting the data, I Huhtaniemi for testosterone analyses and P Pussinen for statistical analyses.

\section{Acknowledgements}

The authors wish to thank BM Eva Andsberg, research nurses Laura Darcy and Annica Maxedius for their excellent job in interviewing the subjects, collecting blood samples, collecting data and registering data. We thank Ms Taina Kirjonen for running the testosterone assays.

\section{References}

1 Morris PD \& Channer KS. Testosterone and cardiovascular disease in men. Asian Journal of Andrology 201214 428-435. (doi:10.1038/aja. 2012.21)

2 Basaria S, Coviello AD, Travison TG, Storer TW, Farwell WR, Jette AM, Eder R, Tennstedt S, Ulloor J, Zhang A et al. Adverse events associated with testosterone administration. New England Journal of Medicine 2010 363 109-122. (doi:10.1056/NEJMoa1000485)

3 Vigen R, O’Donnell CI, Barón AE, Grunwald GK, Maddox TM, Bradley SM, Barqawi A, Woning G, Wierman ME, Plomondon ME et al. Association of testosterone therapy with mortality, myocardial infarction, and stroke in men with low testosterone levels. Journal of the American Medical Association 2013310 1829-1836. (doi:10.1001/jama. 2013.280386)

$4 \mathrm{Xu} \mathrm{L}$, Freeman G, Cowling BJ \& Schooling CM. Testosterone therapy and cardiovascular events among men: a systematic review and metaanalysis of placebo-controlled randomized trials. BMC Medicine 201311 108. (doi:10.1186/1741-7015-11-108)

5 Finkle WD, Greenland S, Ridgeway GK, Adams JL, Frasco MA, Cook MB, Fraumeni JF Jr \& Hoover RN. Increased risk of non-fatal myocardial infarction following testosterone therapy prescription in men. PLoS ONE 20149 e85805. (doi:10.1371/journal.pone.0085805)

6 Corona G, Rastrelli G, Maseroli E, Fralassi N, Sforza A, Forti G, Mannucci E $\&$ Maggi M. Low testosterone syndrome protects subjects with high cardiovascular risk burden from major adverse cardiovascular events. Andrology 20142 741-747. (doi:10.1111/j.2047-2927.2014.00241.x)

7 Araujo AB, Dixon JM, Suarez EA, Murad MH, Guey LT \& Wittert GA. Clinical review: endogenous testosterone and mortality in men: a systematic review and meta-analysis. Journal of Clinical Endocrinology and Metabolism 201196 3007-3019. (doi:10.1210/jc.2011-1137)

8 Corona G, Rastrelli G, Monami M, Guay A, Buvat J, Sforza A, Forti G, Mannucci E \& Maggi M. Hypogonadism as a risk factor for cardiovascular mortality in men: a meta-analytic study. European Journal of Endocrinology 2011165 687-701. (doi:10.1530/EJE-11-0447)

9 Pesonen E, Andsberg E, Ohlin H, Puolakkainen M, Rautelin H, Sarna S \& Persson K. Dual role of infections as risk factors for coronary heart disease. Atherosclerosis 2007192 370-375. (doi:10.1016/j.atherosclerosis.2006.05.018)

10 Pesonen E, El-Segaier M, Persson K, Puolakkainen M, Sarna S, Öhlin H \& Pussinen PJ. Infections as a stimulus for coronary occlusion, obstruction, or acute coronary syndrome. Therapeutic Advances in Cardiovascular Disease 20093 447-454. (doi:10.1177/ 1753944709345598)

11 Alexandersen P, Haarbo J \& Christiansen CH. The relationship of natural androgens to coronary heart disease in males: a review. Atherosclerosis 1996125 1-13. (doi:10.1016/0021-9150(96)05864-9)

12 Ruige JB, Mahmoud AM, De Bacquer D \& Kaufman JM. Endogenous testosterone and cardiovascular disease in healthy men: a metaanalysis. Heart 201197 870-875. (doi:10.1136/hrt.2010.210757)

13 Barrett-Connor E \& Khaw KT. Endogenous sex hormones and cardiovascular disease in men: a prospective population-based study. Circulation 198878 539-545. (doi:10.1161/01.CIR.78.3.539)

14 Kabakci G, Yildirir A, Can I, Unsal I \& Erbas B. Relationship between endogenous sex hormone levels, lipoproteins and coronary atherosclerosis in men undergoing coronary angiography. Cardiology 199992 221-225. (doi:10.1159/000006977)

15 Vikan T, Johnsen SH, Schirmer H, Njølstad I \& Svartberg J. Endogenous testosterone and the prospective association with carotid atherosclerosis in men: the Tromsø study. European Journal of Epidemiology 200924 289-295. (doi:10.1007/s10654-009-9322-2)

16 Canoy D, Barber TM, Pouta A, Hartikainen AL, McCarthy MI, Franks S, Järvelin MR, Tapanainen JS, Ruokonen A, Huhtaniemi IT et al. Serum sex hormone-binding globulin and testosterone in relation to cardiovascular disease risk factors in young men: a population-based study. European Journal of Endocrinology 2014170 863-872. (doi:10.1530/EJE-13-1046)

17 Jeppesen LL, Jørgensen HS, Nakayama H, Raaschou HO, Olsen TS \& Winther K. Decreased serum testosterone in men with acute ischemic stroke. Arteriosclerosis, Thrombosis, and Vascular Biology 199616 749-754. (doi:10.1161/01.ATV.16.6.749)

18 Yeap BB, Alfonso H, Chubb SA, Handelsman DJ, Hankey GJ, Almeida OP, Golledge J, Norman PE \& Flicker L. In older men an optimal plasma testosterone is associated with reduced all-cause mortality and higher dihydrotestosterone with reduced ischemic heart disease mortality, while estradiol levels do not predict mortality. Journal of Clinical Endocrinology and Metabolism 201499 E9-E18. (doi:10.1210/jc.2013-3272)

19 Chatrath R, Ronningen KL, Severson SR, LaBreche P, Jayachandran M, Bracamonte MP \& Miller VM. Endothelium-dependent responses in coronary arteries are changed with puberty in male pigs. American Journal of Physiology. Heart and Circulatory Physiology 2003285 H1168-H1176. (doi:10.1152/ajpheart.00029.2003)

20 Garnick MB. Testosterone replacement therapy faces FDA scrutiny. Journal of the American Medical Association 2015313 563-564. (doi:10.1001/jama.2014.17334)

21 Morgentaler A, Miner MM, Caliber M, Guay AT, Khera M \& Traish AM. Testosterone therapy and cadiovascular risk: advances and controversies. Mayo Clinic Proceedings 201590 1038-1045. (doi:10.1016/j.mayocp.2014.10.011) 
22 Orwoll ES, Chan BK, Lambert LC, Marshall LM, Lewis C \& Phipps KR. Sex steroids, periodontal health, and tooth loss in older men. Journal of Dental Research 200988 704-708. (doi:10.1177/ 0022034509341013)

23 Singh BP, Makker A, Tripathi A, Singh MM \& Gupta V. Association of testosterone and bone mineral density with tooth loss in men with chronic periodontitis. Journal of Oral Science 201153 333-339. (doi:10.2334/josnusd.53.333)

24 Farwell AP. Nonthyroidal illness syndrome. Current Opinion in Endocrinology, Diabetes, and Obesity 201320 478-484. (doi:10.1097/01. med.0000433069.09294.e8)

25 Parle JV, Maisonneuve P, Sheppard MC, Boyle P \& Franklyn JA. Prediction of all-cause and cardiovascular mortality in elderly people from one low serum thyrotropin result: a 10-year cohort study. Lancet 2001358 861-865. (doi:10.1016/S0140-6736(01)06067-6)

26 Gussekloo J, van Exel E, de Craen AJ, Meinders AE, Frölich M \& Westendorp RG. Thyroid status, disability and cognitive function, and survival in old age. Journal of the American Medical Association 2004292 2591-2599. (doi:10.1001/jama.292.21.2591)
27 Brambilla DJ, Matsumoto AM, Araujo AB \& McKinlay JB. The effect of diurnal variation on clinical measurement of serum testosterone and other sex hormone Levels in men. Journal of Clinical Endocrinology and Metabolism 200994 907-913. (doi:10.1210/jc.2008-1902)

28 Huhtaniemi IT, Tajar A, Lee DM, O'Neill TW, Finn JD, Bartfai G, Boonen S, Casanueva FF, Giwercman A, Han TS et al. Comparison of serum testosterone and estradiol measurements in 3174 European men using platform immunoassay and mass spectrometry; relevance for the diagnostics in aging men. European Journal of Endocrinology 2012166 983-991. (doi:10.1530/EJE-11-1051)

29 Taylor AE, Keevil B \& Huhtaniemi IT. Mass spectrometry and immunoassay: how to measure steroid hormones today and tomorrow. European Journal of Endocrinology 2015173 D1-12. (doi:10.1530/EJE-15-0338)

30 Wu FC, Tajar A, Pye SR, Silman AJ, Finn JD, O'Neill TW, Bartfai G, Casanueva F, Forti G, Giwercman A et al. Hypothalamic-pituitarytesticular axis disruptions in older men are differentially linked to age and modifiable risk factors: the European Male Aging Study. Journal of Clinical Endocrinology and Metabolism 200893 1379-1385. (doi:10.1210/ jc.2007-1972)

Received 27 July 2015

Revised version received 8 January 2016

Accepted 15 January 2016 